\section{Dorsal penile nerve block in children under- going circumcision in a day-care surgery}

Francis Serour MD,* Amram Cohen MD FACs, $\dagger$ Avigdor Mandelberg MD, $\ddagger$ Jacques Mori MD,§ Saul Ezra MD§
Purpose: Circumcision is performed under general anaesthesia (GA) with dorsal penile nerve block (DPNB) as an analgesic technique for postoperative pain. The purpose of this study was to compare DPNB as the sole anaesthetic procedure vs GA and DPNB for circumcision in children as an outpatient procedure.

Methods: In a six-month prospective study, 250 boys aged 6 to $17 \mathrm{yr}$ (mean age $11.5 \pm 3.5 \mathrm{yr}$ ) were randomized into two groups. Group A $(n=122)$ received DPNB only prior to circumcision, and Group $B(n=128)$ received $G A+D P N B$. The groups were compared for complications of the block, effectiveness of anaesthesia, operating room time, postoperative time and ease of recovery.

Results: There were no major operative complications in the two groups. Minor block complications, including oedema and haematoma, occurred in 16 (13.1\%) boys in Group $A$ and 27 (21.10\%) boys in Group B (NS). At surgery, 3 (2.6\%) from Group $A$ received additional $G A$ and $I(0.8 \%)$ received additional local anaesthesia. They represent a DPNB failure rate of $3.3 \%$. Mean operating room time was $11 \pm 2.5 \mathrm{~min}$ in Group $A$ and $19 \pm 3.5 \mathrm{~min}$ in Group B, and post-anaesthesia care unit (PACU) time was $51 \pm 10 \mathrm{~min}$ in Group $A$ and $101 \pm 14.5 \mathrm{~min}$ in Group $B(P<0.001)$. Nausea and vomiting in the $P A C U$ were noted in one patient in Group $A$ and in 15 in Group $B(P$ $<0.05)$. Only patients in Group $B$ required additional analgesia and tranquilizers in the PACU $(0$ versus $20 ; P<0.05)$.

\section{Key words}

ANAESTHESIA: paediatric;

ANAESTHETIC TECHNIQUES: penile block.

From the Division of Pediatric Surgery*, the Department of Cardiovascular Surgery†, the Pediatric Pulmonary Division $\ddagger$ and the Department of Anesthesiology§, The Edith Wolfson Medical Center, Holon, and Sackler School of Medicine, Tel Aviv University, Tel Aviv, Israel.

Address correspondence to: Dr. Francis Serour, Division of Pediatric Surgery, The Edith Wolfson Medical Center, PO

Box 5, Holon 58100, Israel.

Phone: 972-3-5028419. Fax: 972-3-5036408.

E-mail: uniqtour@netvision.net.il

Accepted for publication 26th April, 1996.
Conclusions: These data confirm that DPNB has advantages over $G A+D P N B$ for paediatric circumcision in day-care surgery.

Objectif: La circoncision est réalisée sous anesthésie générale ( $A G$ ) associée au bloc du nerf dorsal de la verge (BNDV) pour l'analgésie postopératoire. Cette étude visait à comparer chez des enfant opérés en chirurgie ambulatoire le BNDV seul et l'anesthésie générale avec BNDV.

Méthodes: Pendant une étude prospective de six mois, 250 garçons âgés de 6 à 17 ans (âge moyen 11,5 $\pm 3,5$ ans) avaient été répartis au hasard entre deux groupes. Le groupe $A(n=122)$ recevait un BNDV seul avant la circoncision et le groupe $B(n=128)$ recevait $A G+B N D V$. Les groupes étaient comparés au regard des complications du bloc, de l'efficacité de l'anesthésie, de la durée de l'intervention, de la durée de la période postopératoire et du confort du patient.

Résultats: Il n'y a pas eu de complication opératoires majeures dans aucun des groupes. Des complications mineures dues au bloc, dont l'oedème et l'hématome sont survenues chez 16 (13,3\%) des garçons du groupe A et chez 27 (21,10\%) du groupe $B(N S)$. Au moment de la chirurgie, dans le groupe $A$, on a complété avec de l'anesthésie générale chez trois enfants $(2,6 \%)$ et avec un anesthésique local chez un enfant $(0,8 \%)$. Ce qui établi le taux d'échec du BNDV à 3,3\%. La durée moyenne de l'utilisation de la salle d'opération était de $I I \pm 2,5$ min pour le groupe $A$ et de $19 \pm 3,5$ min pour le groupe $B$. La durée du séjour à l'unité de soins postanesthésiques (USPA) était $51 \pm 10$ min pour le groupe A et de $101 \pm$ 14,5 min pour le groupe $B(P<0,001)$. À l'USPA, des nausées et vomissements sont survenus chez un patient du groupe $A$ et chez 15 du groupe $B(P<0,05)$. À l'USPA, seuls les patients $d u$ groupe $B$ ont eu besoin d'analgésie additionnelle et de tranquillisants (0 vs 20; $P<0,05$ ).

Conclusion: Ces données confirment certains avantages de $B N D V$ sur $A G+B N D V$ pour la circoncision en chirurgie ambulatoire.

Dorsal penile nerve block (DPNB) is an effective and safe method for pain relief during circumcision. ${ }^{1,2}$ Circumcision in children is performed under general 
anaesthesia (GA) to reduce fear and DPNB is used for postoperative analgesia. ${ }^{1-5}$ Penile block is used as the sole intraoperative anaesthetic in neonates and adults . ${ }^{6-8}$

In a previous retrospective study, ${ }^{9}$ we showed that DPNB was effective as the sole anaesthetic in children undergoing circumcision. The present study tests the hypothesis that DPNB is effective as the sole anaesthetic for pediatric circumcision in a prospective, randomized fashion.

\section{Methods}

A prospective study was conducted over six months among 257 children aged 6 to $17 \mathrm{yr}$ (mean age $11.5 \pm$ $3.5 \mathrm{yr}$ ) who underwent circumcision as an outpatient procedure. The boys were randomly allocated for circumcision with DPNB alone (Group A) or GA + DPNB (Group B). The evaluation could not be blinded since those performing the procedure were also those evaluating the patients. Informed consent was obtained from parents or guardians, in accordance with the ethical requirements of our facility. No child received premedication, additional anaesthesia or analgesia. Routine monitoring (pulse oximeter, blood pressure and ECG) was used, and the children were anaesthetized with an inhalational technique using oxygen, isoflurane and nitrous oxide. The patients were all managed without tracheal intubation.

For Group A, DPNB was performed by the anaesthetist in the preoperative room $20 \mathrm{~min}$ before the surgical procedure, while a second anaesthetist monitored the child being operated upon. Under these circumstances, DPNB took two to five minutes and this was not calculated in the operating room time. In Group B, DPNB was administered by another anaesthetist in the operating room following GA. For those in Group A who rejected DPNB because of fear or other psychological factors, it was administered after GA: these patients were excluded from the study.

The block was administered with patients in the supine position, using a 23 gauge needle to inject a solution of $1 \mathrm{mg} \cdot \mathrm{kg}^{-1}$ lidocaine $2 \%$ mixed with $0.5 \mathrm{mg} \cdot \mathrm{kg}^{-1}$ bupivacaine $0.5 \%$ without epinephrine, to a maximum dose of $10 \mathrm{ml}$. The needle was inserted in the midline at the base of the penis up to the symphysis pubis. ${ }^{10,11}$ One paramedian injection of local anaesthetic was performed in order to block the dorsal nerves on both sides. Additional analgesia was administered on the raphe line at the border between the scrotum and penis to alleviate pain from the perineal nerves. ${ }^{8,9}$ The solution was injected in a ratio of $75-25 \%$ on the dorsal and ventral aspects of the penis, respectively. In Group A children, analgesia was confirmed by gently pinching the skin of the penis with forceps about $15 \mathrm{~min}$ after injection. Children were asked about the level of their discomfort by the anaesthetist before incision. In the event of insufficient analgesia, a second test was performed five minutes later. In the presence of persistent pain, fear or refusal of surgery, GA was administered.

Surgery alternated between two operating rooms with the block performed by the anaesthetist while surgery progressed in the other room, monitored by the second anaesthetist. The procedure involved transection of the foreskin, haemostasis by electrocautery and suture of the skin edges with 3-0 plain catgut. After incision, patients were asked to report any kind of sensation or pain during surgery. Based on the child's reply and behaviour, the intensity of the pain was graded by both the surgeon and the anaesthetist on the following scale: (1) totally cooperative and no pain, (2) totally cooperative with mild pain, (3) agitated but manageable, reporting moderate pain, (4) uncooperative and agitated with severe pain, and (5) total refusal to continue. In patients with severe intraoperative pain (grades 3 to 5 ), the surgical procedure was suspended and analgesia was supplemented with either GA or local anaesthesia by subcutaneous injection of $0.1 \mathrm{ml}$ lidocaine $2 \%$ at the pain site. The need for supplemental anaesthesia was recorded as a DPNB failure. Operating room time, defined as the time of patient placement on the operating table until his removal, was recorded in all cases.

In the postoperative period, patients were observed in the post-anaesthesia care unit (PACU). We defined PACU time as the time that they entered the room until the time of discharge. Oral intake was immediately permitted in those receiving only DPNB. Analgesics (paracetamol) and tranquilizers (hydroxyzine $\mathrm{HCl}$ ) were administered as needed. The surgeon discharged the children from the PACU following a period of observation, and after examining the patient for evidence of complications. Discharge criteria included an alert and oriented patient who voided spontaneously. Vomiting, postoperative pain, need for medications and PACU time were recorded by the PACU nurses.

Statistical analysis was performed using Fisher Exact, Chi-square $\left(\chi^{2}\right)$, and Student's $t$ tests, with all findings being reported with standard deviation.

\section{Results}

The study included 257 boys undergoing circumcision. Seven randomized to Group A refused DPNB, and they were excluded from the study. The remaining $250 \mathrm{com}-$ prised the study population, and were divided into Group A (122) and Group B (128). The study group age ranged between 6 to 17 (mean $11.5 \pm 3.5$ ) yr; mean age in Group A was 11.5 \pm 3 and in Group B was $11.5 \pm$ 3.5 . 
TABLE I Minor complications among the study population.

\begin{tabular}{|c|c|c|c|c|c|c|c|c|c|c|c|}
\hline & \multirow[b]{2}{*}{$n$} & \multicolumn{2}{|c|}{ Oedema } & \multicolumn{2}{|c|}{ Haematoma } & \multicolumn{2}{|c|}{ Vomiting } & \multicolumn{2}{|c|}{ Postop agitation } & \multicolumn{2}{|c|}{ Medication } \\
\hline & & $n$ & $\%$ & $n$ & $\%$ & $n$ & $\%$ & $n$ & $\%$ & $n$ & $\%$ \\
\hline Group A & 122 & 13 & 10.6 & 3 & 2.3 & 1 & 0.8 & 1 & 0.8 & & \\
\hline Group B & 128 & 18 & 14 & 9 & 7.4 & 15 & 11.7 & 9 & 7.0 & 19 & 14.8 \\
\hline Total & 250 & 31 & 12.4 & 12 & 4.8 & 16 & 6.4 & 10 & 4 & 19 & 7.6 \\
\hline
\end{tabular}

TABLE II Average operating and PACU times in Groups A and B

\begin{tabular}{lllc}
\hline & Patients $-n$ & OR time $-\min$ & PACU time - min \\
\hline Group A & 122 & $11 \pm 2.5(6-22)$ & $51 \pm 10(30-110)$ \\
Group B & 128 & $19 \pm 3.5(8-26)$ & $101 \pm 14.5(90-120)$ \\
$P$ & & $<0.001$ & $<0.001$ \\
\hline
\end{tabular}

TABLE III Age and operative parameter comparisons between patients receiving supplemental medication

\begin{tabular}{llll}
\hline & $\begin{array}{l}\text { DPNB success } \\
n=118\end{array}$ & $\begin{array}{l}\text { DPNB failure } \\
n=4\end{array}$ & $P$ \\
\hline Age yr & $11.5 \pm 3$ & $7 \pm 1.4$ & $<0.001$ \\
OR time $-\min$ & $11 \pm 2.5(6-18)$ & $20 \pm 1.5(18-22)$ & $<0.001$ \\
PACU time - min & $51 \pm 10(30-110)$ & $75 \pm 22(40-120)$ & $<0.001$ \\
\hline
\end{tabular}

Mean \pm SD (range)

No major complications were noted with the use of DPNB. Minor complications included oedema between the skin and Buck's fascia and haematoma (Table I). No serious bleeding was noted during surgery.

All patients in Group A were considered to have had good analgesia before the surgical procedure. In four boys, supplemental anaesthesia was necessary during the procedure; three received GA and one local anaesthesia. The operating room and PACU times were shorter $(P<0.001)$ for Group A patients (Table II). The four children from Group A, who required supplemental anaesthesia were younger than the group as a whole, and required longer operating room and PACU times $(P$ $<0.001$ ) (Table III).

In the recovery period, there was no urinary retention. Nausea and vomiting were noted in $16(6.4 \%)$ children overall; one from Group A and 15 from Group B $(P<$ 0.05 ) (Table I). They were treated with metoclopramide as needed. Analgesics and tranquilizers were given to 19 (7.6\%) children, all from Group B $(P<0.05)$.

\section{Discussion}

Penile block is frequently used for circumcision, in neonates as the sole agent $t^{6,7,12}$ or in association with GA in children. ${ }^{1,5,10}$ It is a safe, simple and effective proce- dure for decreasing postoperative pain..$^{1,4,5,12,13}$ It also reduces behavioural distress and diminishes adrenocortical stress response. ${ }^{14}$ Successful block avoids the need for supplemental postoperative analgesia for 6 to 24 hr. ${ }^{1,5,13,15,16}$ Early discharge is possible ${ }^{15}$ with a more rapid recovery ${ }^{5,14,17}$ and earlier micturition. ${ }^{4}$ We have demonstrated that in older children, DPNB may be used as the sole source of anaesthesia with a high rate of success. This technique eliminates the risk and postoperative morbidity of GA, permits shorter operating room and PACU times, and an easier recovery period without nausea, vomiting or drowsiness. ${ }^{9}$ All these are advantages for a day-care surgery procedure.

We encountered no technical difficulties in performing DPNB, nor were there any severe block-related complications due to local oedema or haematoma. The frequency of minor complications, such as bleeding, haematoma and minor bruising was similar to previous results. ${ }^{14}$ Rare major complications, such as toxic absorption of the anaesthetic ${ }^{2}$ or gangrene of the glans ${ }^{19}$ were not seen.

Operative room and PACU times were shorter with DPNB alone, due to the lack of induction and recovery from GA times (Figure 1 and Table II). The procedure with block alone did require more attention from the anaesthetist, but saved operating room time. A reduction in the incidence of nausea and vomiting, postoperative agitation, pain and need for medications was also noted in Group A patients (Figure 2).

Reported failure rate of DPNB with or without GA varies from 2.9 to $6.7 \%,{ }^{4-7,15}$ and has been related to technical difficulties ${ }^{18}$ or failure of analgesia of the perineal nerves. ${ }^{9,10}$ Thus, we performed DPNB with an additional injection on the raphe line and DPNB failure was $3.3 \%$ in Group A. These patients were younger than those who had a successful block. This may be related to increased anxiety and fear during local anaesthesia and surgery. We did not consider patients who initially refused DPNB as treatment failures, but rather excluded them from the study. If these boys were also considered as DPNB failures, then the failure rate would be $8.5 \%$.

Our study suffers from a number of limitations. First, since the same anaesthetists performed both the procedure and the evaluation, the study was not blinded. This 


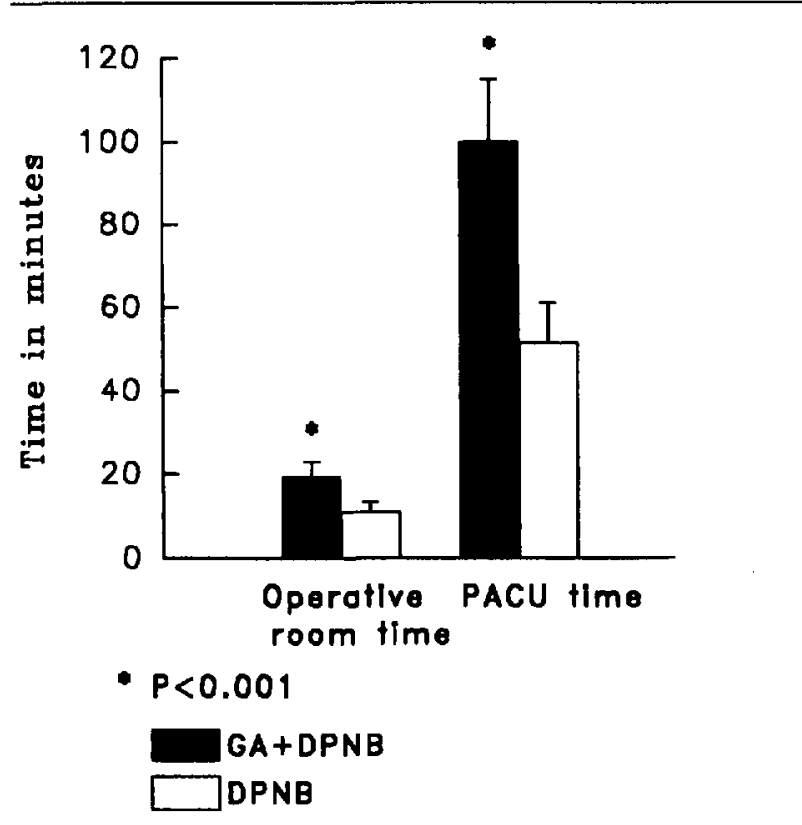

FIGURE 1 Mean operating room and PACU times.

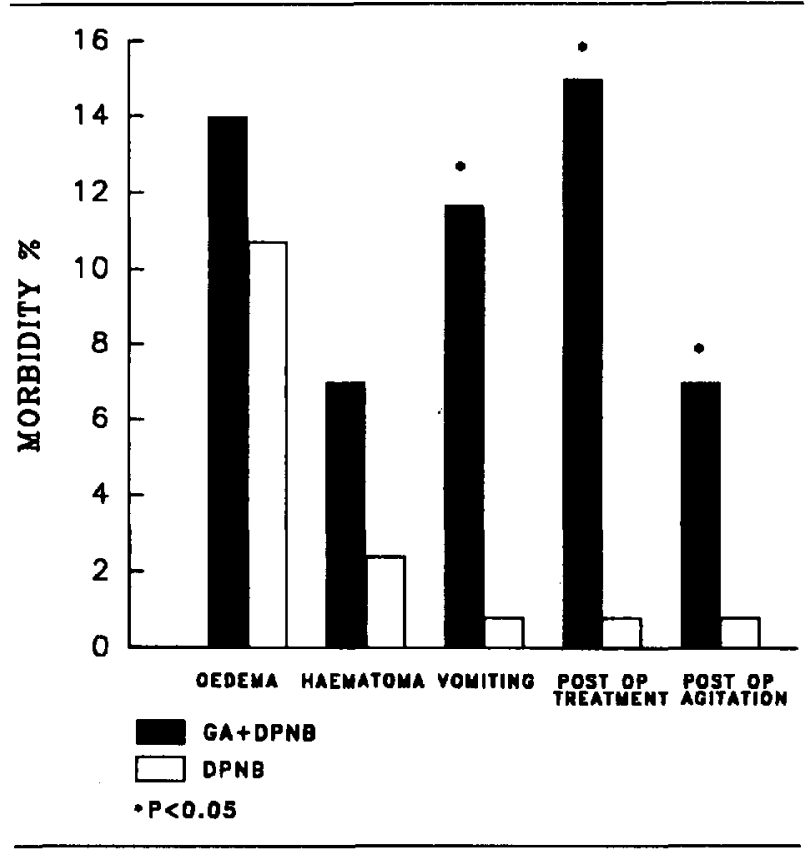

FIGURE 2 Postoperative morbidity

was particularly troublesome, since the assessment of pain was subjectively performed by the surgeon and the anaesthetist judging the patient's response. Second, while we proved that less operating room time is required for patients receiving DPNB alone, the time in the induction room was not included in our calculations.
This time was not great in our setting, since we have sufficient personnel and lack operative rooms. We acknowledge that in a setting where personnel are the limiting factor, the benefit of this approach will be greatly reduced.

In conclusion, DPNB alone is a good method of anaesthesia for children undergoing circumcision. The technique eliminates the risks of $\mathrm{GA}$ and results in reduced operating room and PACU times, as well as reduced postoperative morbidity. Thus, DPNB is an appropriate procedure for outpatient surgery. For older children scheduled for circumcision, DPNB should be performed without $\mathrm{GA}$ whenever possible.

\section{Acknowledgments}

We thank Sally Esakov for her technical assistance.

\section{References}

1 Soliman $M G$, Tremblay NA. Nerve block of the penis for postoperative pain relief in children. Anesth Analg 1978; 57: 495-8.

2 Goulding FJ. Penile block for postoperative pain relief in penile surgery. J Urol 1981; 126: 337-8.

3 Hersh SP. Psychological implications of operations in children. In: Randolph JG, Ravitch MM, O'Neill JA Jr, Rowe MI (Eds.). Pediatric Surgery, Vol 4. Chicago: Year Book Medical Publishers Inc., 1986: 125-9.

4 Vater $M$, Wandless $J$. Caudal or dorsal nerve block? A comparison of two local anaesthetic techniques for postoperative analgesia following day case circumcision. Acta Anaesthesiol Scand 1985; 29: 175-9.

5 Lau JTK. Penile block for pain relief after circumcision in children. A randomized, prospective trial. Am J Surg 1984; 147: 797-9.

6 Maxwell LG, Yaster M, Wetzel RC, Niebyl JR. Penile nerve block for newborn circumcision. Obstet Gynecol 1987; 70: 415-9.

7 Kirya $C$, Werthmann $M W$. Neonatal circumcision and penile dorsal nerve block - a painless procedure. J Pediatr 1978; 92: 998-1000.

8 Serour F, Mori J, Barr J. Optimal regional anesthesia for circumcision. Anesth Analg 1994; 79: 129-31.

9 Serour F, Reuben S, Ezra S. Circumcision in children with penile block alone. J Urol 1995; 153: 474-6.

10 Dalens $B$, Vanneuville $G$, Dechelotte $P$. Penile block via the subpubic space in 100 children. Anesth Analg 1989; 69: 41-5.

11 Brown TCK, Weidner NJ, Bouwmeester J. Dorsal nerve of penis block - anatomical and radiological studies. Anaesth Intensive Care 1989; 17: 34-8.

12 Arnett RM, Jones JS, Horger ED. Effectiveness of $1 \%$ lidocaine dorsal penile nerve block in infant circumcision. Am J Obstet Gynecol 1990; 163: 1074-80. 
13 Sfez M, Le Mapihan Y, Mazoit X, Dreux-Boucard H. Local anesthetic serum concentrations after penile nerve block in children. Anesth Analg 1990; 71: 423-6.

14 Stang HJ, Gunnar MR, Snellman L, Condon LM, Kestenbaum $R$. Local anesthesia for neonatal circumcision. Effects on distress and cortisol response. JAMA 1988; 259: 1507-11.

15 Tree-Trakarn T, Pirayavaraporn S. Postoperative pain relief for circumcision in children: comparison among morphine, nerve block, and topical analgesia. Anesthesiology 1985; 62: 519-22.

16 Carlsson P. Svensson J. The duration of pain relief after penile block to boys undergoing circumcision. Acta Anaesthesiol Scand 1984; 28: 432-4.

17 Dixon S, Snyder J, Holve R, Bromberger $P$. Behavioral effects of circumcision with and without anesthesia. J Dev Behav Pediatr 1984; 5: 246-50.

18 Masciello AL. Anesthesia for neonatal circumcision: local anesthesia is better than dorsal penile nerve block. Obstet Gynecol 1990; 75: 834-8.

19 Sara CA, Lowry CJ. A complication of circumcision and dorsal nerve block of the penis. Anaesth Intensive Care 1985; 13: 79-85. 